Research Journal of Applied Sciences, Engineering and Technology 5(20): 4791-4795, 2013

DOI:10.19026/rjaset.5.4321

ISSN: 2040-7459; e-ISSN: 2040-7467

(C) 2013 Maxwell Scientific Publication Corp.

Submitted: January, 19, $2012 \quad$ Accepted: May 18, 2012

Published: May 15, 2013

\title{
Research Article \\ Application of Particle Swarm Optimization for Optimal Distributed Generation Allocation to Voltage Profile Improvement and Line Losses Reduction in Distribution Network
}

\author{
${ }^{1}$ Mohammad Shahab Arkan and ${ }^{2}$ Hamed Salehi \\ ${ }^{1}$ Department of Physics, \\ ${ }^{2}$ Department of Electrical Engineering, Yazd Branch, Islamic Azad University, Yazd, Iran
}

\begin{abstract}
Distributed Generation (DG) had created a challenge and an opportunity for developing various novel technologies in power generation. The rate and size of DG implementation have o be determined. The increasing need of electricity and establishing powerhouses, as well as to spend a great amount of time to build powerhouses, indicate the necessity of distributed generation in small size and close to the consumer location. In this study, selecting a part of Tehran network, attempts to investigate the effects of distributed generation on line losses and voltage profile using PSO. The introduction of PSO based DG in a distribution system offers several benefits: Significant voltage profile improvement, Considerable line loss reduction, Improves system reliability and etc. The optimum value of the DG, also obtained increases the maximum load ability of the system. The proposed method is tested on a system and the results of the simulation carried out will be given. Finally the results are compared to system without installation DG. The method has a potential to be a tool for identifying the best location and rating a DG to be installed for improving voltage profile and reduce losses.
\end{abstract}

Keywords: DG allocation, distributed generation, loss reduction, particle swarm optimization, voltage profile

\section{INTRODUCTION}

Distributed Generation which is at first offered for the access of high reliability for sensitive consumers has now been offered as one of suitable methods in providing power according to its considerable positive effect on generation and on the final price of power. The necessity of fundamental change in generation systems and energy transition has been taken for granted as power industry develops. In very early days once man feels he needs electricity energy more and more for different purposes, the energy generation was in the form of distributed generation. Distributed generation usually refers to generation of any kind of energy in pretty low capacities which is operated close to its location or the place of consuming without considering the used technologies which use recycled resources to generate power (Nara et al., 2001).

Considering high costs in transition and distribution, the distributed generators will be given this opportunity to provide cheaper generated power for customers. Practically, this system can be installed and used inside or near the location of the final consumer as a medium of power generation.

What makes power systems designers interested in establishing a large power house to generate power is to provide large consumption loads, heat efficiency increasing and exploitation costs. It is also significant to note that applying DG, will not be always economically rescannable. After all, regarding other benefits of these generations, they will be helpful application. Some of its advantages are emergent power generation, power quality, high reliability, voltage security improvement and loss reduction (Khanjanzadeh et al., 2011).

Distributed Generations be able to reduce the network losses for the reason that they produce the power in the nearness of load, so it is better to allocate DG units in places that they can supply a higher loss reduction. For the reason that DGs are so costly, loss reduction is a very essential object for DGs allocation. Power losses in distribution systems vary with various factors dependent on configuration of the system. Power losses being able to be divided into two parts: Reactive Power and Real Power. The reactive element causes the reactive losses and real power loss is produced due to the resistance of lines (Rahman et al., 2004; El-Khattam et al., 2004, 2005).

The methodology proposed in this study aims to optimize the allocation and sizing of DG units in order to minimize the electrical losses in primary distribution network and to guarantee acceptable voltage profile.

\section{PARTICLE SWARM OPTIMIZATION}

Particle Swarm Optimization (PSO) is a population-based optimization method first proposed by 


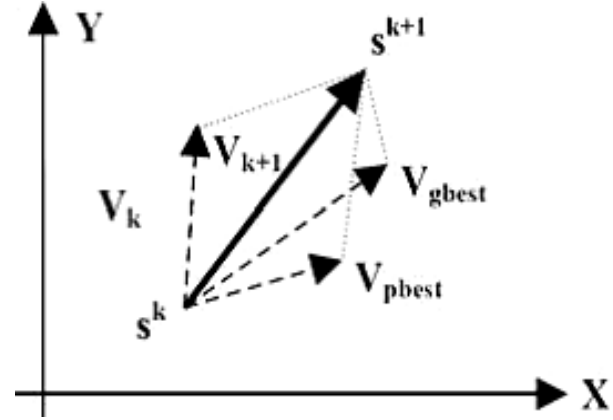

Fig. 1: Concept of a searching point by PSO

Kenedy and Eberhart (1995) and Eberhart and Shi (2000), inspired by social behavior of bird flocking or fish schooling. The PSO as an optimization tool provides a population-based search procedure in which individuals called particles change their position (state) with time. In a PSO system, particles fly around in a multidimensional search space. During flight, each particle adjusts its position according to its own experience (This value is called $\mathrm{P}_{\text {best }}$ ) and according to the experience of a neighboring particle (This value is called $\mathrm{G}_{\text {best }}$ ), made use of the best position encountered by itself and its neighbor (Fig. 1).

This modification can be represented by the concept of velocity. Velocity of each agent can be modified by the following equation:

$$
\begin{aligned}
& \mathrm{V}_{\mathrm{id}}{ }^{\mathrm{k}+1}=\mathrm{v}_{\mathrm{id}}{ }^{\mathrm{k}+\mathrm{c}}+\mathrm{c}_{1} \text { rand } \times\left(\mathrm{P}_{\text {best }_{\mathrm{id}}}-\mathrm{S}_{\mathrm{id}}{ }^{\mathrm{k}}\right) \\
& +\mathrm{c}_{2} \text { rand } \times\left(\mathrm{g}_{\text {best }_{\mathrm{id}}}-\mathrm{S}_{\mathrm{id}}{ }^{\mathrm{k}}\right)
\end{aligned}
$$

By Using the above equation, a certain velocity, which gradually get close to $P_{\text {best }}$ and $G_{\text {best }}$ can be calculated. The current position (searching point in the solution space) can be modified by the following equation:

$$
\mathrm{S}_{\mathrm{id}}{ }^{(\mathrm{k}+1)}=\mathrm{S}_{\mathrm{id}}{ }^{\mathrm{k}}+\mathrm{V}_{\mathrm{id}}{ }^{(\mathrm{k}+1)}
$$

$$
\mathrm{i}=1,2, \ldots, \mathrm{n} \quad d=1,2, \ldots, m
$$

where, $s^{k}$ is current searching point, $s^{k+1}$ is modified searching point, $\mathrm{v}^{\mathrm{k}}$ is current velocity, $\mathrm{v}^{\mathrm{k}+1}$ is modified velocity of agent $i, v P_{\text {best }}$ is velocity based on $P_{\text {best }}$, $\operatorname{vg}_{\text {best }} \mathrm{t}$ is velocity based on $\mathrm{g}_{\text {best }}, \mathrm{n}$ is number of particles in a group, $\mathrm{m}$ is number of members in a particle, $\mathrm{P}_{\text {best }} \mathrm{i}$ is $\mathrm{P}_{\text {best }}$ of agent $\mathrm{i}, \mathrm{g}_{\text {best }} \mathrm{i}$ is $\mathrm{g}_{\text {best }}$ of the group, $w_{i}$ is weight function for velocity of agent $\mathrm{i}, \mathrm{C}_{\mathrm{i}}$ is weight coefficients for each term.

The following weight function is used:

$$
\mathrm{w}_{\mathrm{i}}=\mathrm{w}_{\max }-\frac{\left(\mathrm{w}_{\max }-\mathrm{w}_{\min }\right)}{\mathrm{k}_{\max }} \mathrm{k}
$$

where, $\mathrm{w}_{\min }$ and $\mathrm{w}_{\max }$ are the minimum and maximum weights respectively. $\mathrm{K}$ and $\mathrm{k}_{\max }$ are the current and maximum iteration. Appropriate value ranges for $\mathrm{C} 1$ and $\mathrm{C} 2$ are 1 to 2 , but 2 is the most appropriate in many cases. Appropriate values for $\mathrm{w}_{\min }$ and $\mathrm{w}_{\max }$ are 0.4 and 0.9 Eberhart and Shi (2000), respectively.

\section{PROBLEM FORMULATION}

The proposed study aims at minimizing the combined objective function designed to reduce power loss and also improve voltage profile. The main objective function is defined as:

$$
\operatorname{minf}=\mathrm{P}_{\text {loss }}+\sum_{\mathrm{i}=0}^{\mathrm{n}} \mu_{p}\left(1-V_{p}\right)^{2}
$$

where, $\mu_{P}$ is the penalty factor of bus voltages and is taken as 200, P loss is the real power loss obtained from the load flow solution at the base case, VP is the voltage profile of the buses. The fitness function is defined as:

$$
\text { fit }=1 /(1+f)
$$

\section{PROPOSED ALGORITHM}

The PSO-based approach for solving the OPDG problem to minimize the loss takes the following steps:

Step 1: Input line and bus data and bus voltage limits.

Step 2: Calculate the loss using distribution load flow based on backward-forward sweep.

Step 3: Randomly generates an initial population (array) of particles with random positions and velocities on dimensions in the solution space. Set the iteration counter $\mathrm{k}=0$.

Step 4: For each particle if the bus voltage is within the limits, calculate the total loss. Otherwise, that particle is infeasible.

Step 5: For each particle, compare its objective value with the individual best. If the objective value is lower than $\mathrm{P}_{\text {best }}$, set this value as the current best and record the corresponding particle position.

Step 6: Choose the particle associated with the minimum individual best $P_{\text {best }}$ of all particles and set the value of this $P_{\text {best }}$ as the current overall best $G_{\text {best }}$. 


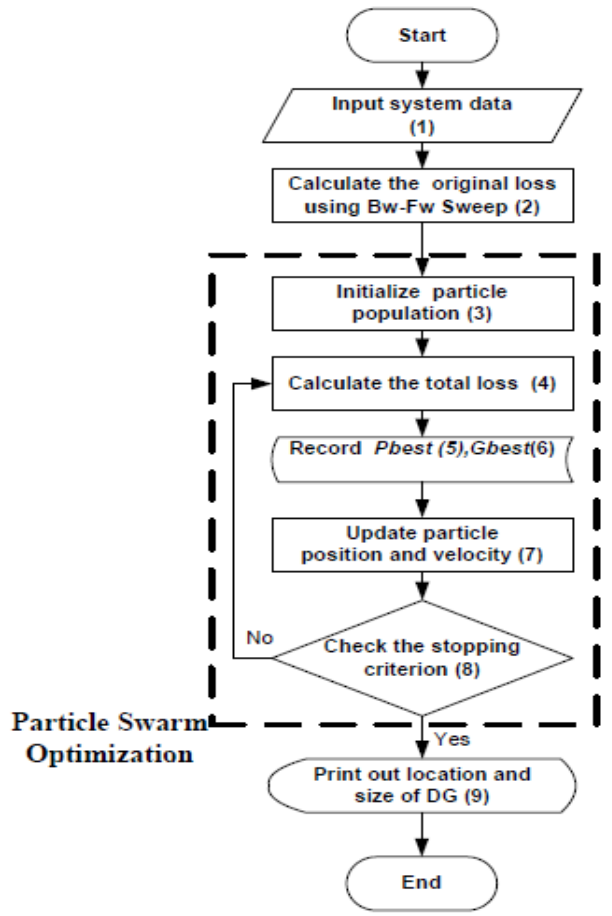

Fig. 2: PSO-OPDG computational procedure

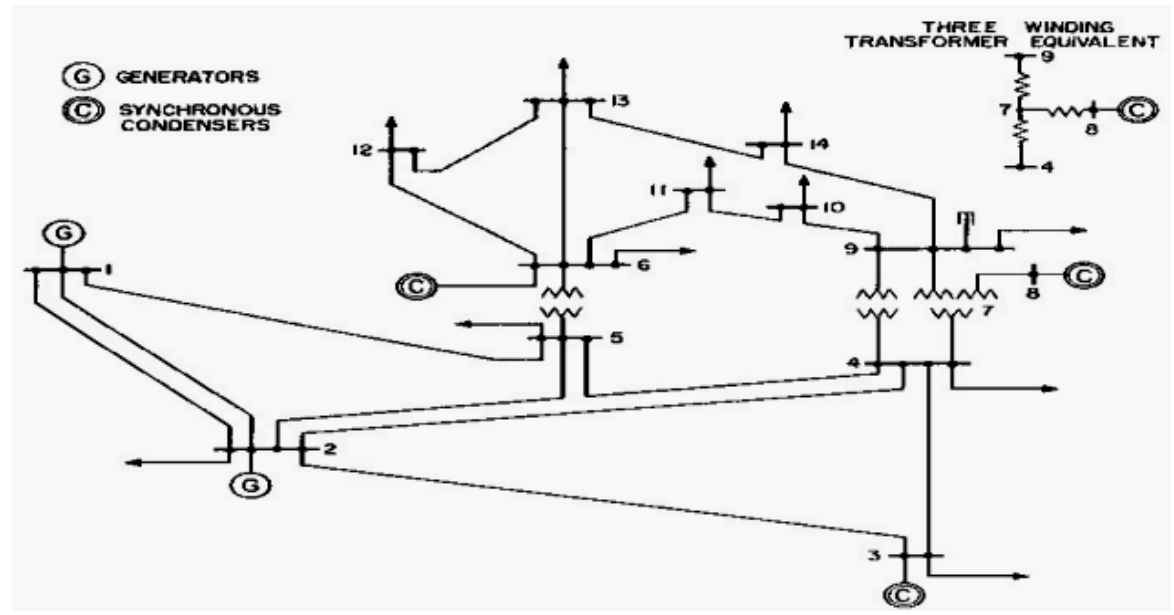

Fig. 3: Standard 14 bus IEEE system

Step 7: Update the velocity and position of particle using (2) and (3), respectively.

Step 8: If the iteration number reaches the maximum limit, go to Step 9. Otherwise, set iteration index $\mathrm{k}=\mathrm{k}+1$ and go back to Step 4.

Step 9: Print out the optimal solution to the target problem. The best position includes the optimal locations and size of DG or multi-DGs and the corresponding fitness value representing the minimum total real power loss. PSO-OPDG computational procedure is shown in Fig. 2.

\section{CASE STUDY}

The single line diagram of the network is illustrated in Fig. 3. It was selected from IEEE-14 bus Network. Table 1 and 2 provide the data of lines and buses:

In Table 1 and 2 the lines data and Busses Data will be shown.

The bus system is with the total load of 259 MW and 73.5 MVar. The original total real power loss and reactive power loss in the system are $13.393 \mathrm{MW}$ and 54 MVAR, respectively. Initially, a load flow was run for 
Res. J. Appl. Sci. Eng. Technol., 5(20): 4791-4795, 2013

\begin{tabular}{lllll}
\multicolumn{5}{l}{ Table 1: Lines data } \\
\hline From & To & Rohm & Xohm & B \\
\hline 1 & 2 & 0.019 & 0.0592 & 0.053 \\
1 & 5 & 0.054 & 0.2230 & 0.049 \\
2 & 3 & 0.047 & 0.1980 & 0.044 \\
2 & 4 & 0.058 & 0.1763 & 0.034 \\
2 & 5 & 0.057 & 0.1739 & 0.035 \\
3 & 4 & 0.067 & 0.1710 & 0.013 \\
4 & 5 & 0.013 & 0.0421 & 0.000 \\
4 & 7 & 0.000 & 0.2091 & 0.000 \\
4 & 9 & 0.000 & 0.5562 & 0.000 \\
5 & 6 & 0.000 & 0.2520 & 0.000 \\
6 & 11 & 0.095 & 0.1989 & 0.000 \\
6 & 12 & 0.123 & 0.2558 & 0.000 \\
6 & 13 & 0.066 & 0.1303 & 0.000 \\
7 & 8 & 0.000 & 0.1762 & 0.000 \\
7 & 9 & 0.000 & 0.1100 & 0.000 \\
9 & 10 & 0.032 & 0.0845 & 0.000 \\
9 & 14 & 0.127 & 0.2704 & 0.000 \\
10 & 11 & 0.082 & 0.1921 & 0.000 \\
12 & 13 & 0.221 & 0.1999 & 0.000 \\
13 & 14 & 0.171 & 0.3480 & 0.000 \\
\hline
\end{tabular}

\begin{tabular}{lll} 
Table 2: Buses data & & \\
\hline Bus number & $\mathrm{P}$ & $\mathrm{Q}$ \\
\hline 1 & 0.0 & 0.0 \\
2 & 21.7 & 12.7 \\
3 & 94.2 & 19.0 \\
4 & 47.8 & -3.9 \\
5 & 7.6 & 1.6 \\
6 & 11.2 & 7.5 \\
7 & 0.0 & 0.0 \\
8 & 0.0 & 0.0 \\
9 & 29.5 & 16.6 \\
10 & 9.0 & 5.8 \\
11 & 3.5 & 1.8 \\
12 & 6.1 & 1.6 \\
13 & 13.5 & 5.8 \\
14 & 14.9 & 5.0 \\
\hline
\end{tabular}

Table 3: Results of power flow and harmonic power flow without installation of DG

\begin{tabular}{lll}
\hline BUS & V (without DG) & V (with DG) \\
\hline 1 & 1.060 & 1.060 \\
2 & 1.045 & 1.045 \\
3 & 1.010 & 1.010 \\
4 & 1.019 & 1.014 \\
5 & 1.020 & 1.017 \\
6 & 1.070 & 1.070 \\
7 & 1.062 & 1.051 \\
8 & 1.090 & 1.090 \\
9 & 1.056 & 1.034 \\
10 & 1.051 & 1.019 \\
11 & 1.057 & 1.041 \\
12 & 1.055 & 1.044 \\
13 & 1.050 & 1.030 \\
14 & 1.036 & 1.014 \\
\hline
\end{tabular}

the case study without installation of DG. The results are illustrated in Table 3.

\section{SIMULATION RESULTS}

In this study we compare 14 buses system with and without using DG. The PSO method is used to optimize

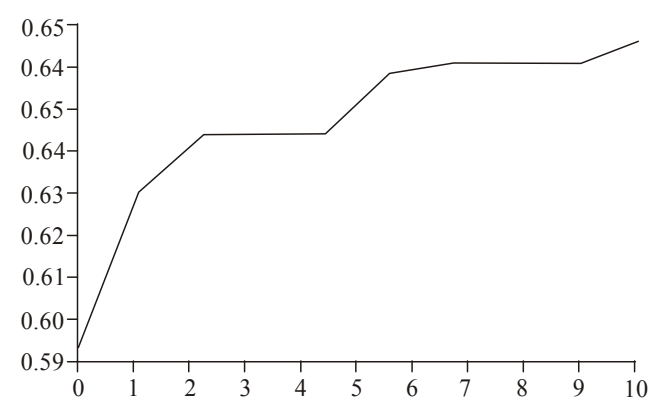

Fig. 4: Fitness function with DG

Table 4: Fitness function without DG

\begin{tabular}{llll}
\hline \multicolumn{5}{l}{} & & Fitness function \\
\hline \multicolumn{5}{l}{ Without DG installation } & 0.74 \\
\hline \multicolumn{5}{l}{ Table 5: Optimum capacity and location } \\
\hline Method & Bus no & DG capacity & Fitness function \\
\hline By PSO & 14 & 17.3MW-J14.6MVAR & 0.79 \\
& 4 & 20MW-J15.6MVAR & \\
& 10 & $16.7 \mathrm{MW}-J 20 \mathrm{MVAR}$ & \\
\hline
\end{tabular}

DG capacity and allocation. This method is implemented with MATLAB software.

The results of optimal capacity and location of DG for case study by PSO is illustrated in Table 4 and 5 and Fig. 4. So results are presented in following:

Using DG in best location considerably reducing line losses and improve voltage profile.

\section{CONCLUSION}

In this study, the results of applying Particle Swarm Optimization to the optimal allocation of DGs in distribution networks were presented.

The effectiveness of the proposed algorithm in solving DG allocation problem was demonstrated through a numerical example. The results of the proposed method as applied to 14-bus of system, clearly show that DG can improve the voltage profile and reduce electrical line losses. Both sizing and locations of DG have to be considered together very carefully to capture the maximum benefits of DG.

\section{REFERENCES}

Eberhart, R.C. and Y. Shi, 2000. Comparing inertial weights and Constriction factor in particle Swarm optimization. Proceeding of the International Congress on Evaluating Computation, Santiago, California, IEEE Service Center, Piscataway, NJ, pp: 84-88.

El-Khattam, W., K. Bhattacharya, Y. Hegazy and M.M.A. Salama, 2004. Optimal investment planning for distributed generation in a competitive electricity market. IEEE Trans. Power Syst., 19: 1674-1684. 
El-Khattam, W., Y.G. Hegazy and M.M.A. Salama, 2005. An integrated distributed generation optimization model for distribution system planning. IEEE Trans. Power Syst., 20: 1158-1165.

Kenedy, J. and R. Eberhart, 1995. Particle swarm optimizer. IEEE International Conference on eural Networks (Perth, Australia), IEEE Service Center Piscataway, NJ, IV, pp: 1942-1948.

Khanjanzadeh, A., M. Sedighzadeh and A. Rezazade, 2011. DG allocation using Clonal Selection Algorithm (CSA) to minimize losses and improve voltage security. Int. Rev. Mod. Simul. (I.RE.MO.S.), 4(1).
Nara, K., Y. Hayashi, K. Ikeda and T. Ashizawa, 2001. Application of tabu search to optimal placement of distributed generators. Proceeding of IEEE Power Engineering Society Winter Meeting, pp: 918-923.

Rahman, T.K.A., S.R.A. Rahim and I. Musirin, 2004. Optimal allocation and sizing of embedded generators. Proceeding of National Power and Energy Conference, pp: 288-294. 